\section{DURATION OF CARDIOPULMONARY BYPASS IN PEDIATRIC CARDIAC SURGERY IS NOT ASSOCIATED WITH POSTOPERATIVE INFECTIONS}

\author{
S.O. Algra ${ }^{1,2}$, M.M.P. Driessen², \\ A.W.L. Schadenberg ${ }^{2}$, A.N.J. Schouten ${ }^{2}$, F. Haas ${ }^{1}$, \\ C.W. Bollen², N.J.G. Jansen ${ }^{2}$ \\ ${ }^{1}$ Department of Pediatric Cardiothoracic Surgery, \\ ${ }^{2}$ Department of Pediatric Intensive Care, University \\ Medical Center Utrecht, Utrecht, The Netherlands
}

Background and aims: In pediatric cardiac surgery, cardiopulmonary bypass (CPB) is frequently employed. CPB is known to initiate a systemic inflammatory response, although other factors like anesthesia, ischemia/ reperfusion and the surgical procedure itself may play a role. The systemic inflammation is composed of a pro- and anti-inflammatory phase, of which the latter can lead to postoperative infections. We hypothesised that longer duration of CPB in pediatric cardiac surgery is associated with increased occurrence of postoperative infections.

Methods: All pediatric patients undergoing cardiac surgery with CPB from April 2006 until May 2009 were included in a retrospective analysis. Postoperative infections were categorised according to Centre of Disease Control-criteria. Logistic regression was used to discriminate whether duration of CPB was associated with postoperative infections, and whether this relationship was confounded by variables such as weight, surgical complexity and lowest intra-operative temperature.

Results: In 364 patients, 412 procedures were performed (median age 29 weeks). An infection occurred following $25 \%$ of the procedures (median start on postoperative day 7). The most common were blood stream infections (25\% of all infections) and surgical site infections (26\%). In univariate analysis, duration of CPB was associated with the occurrence of postoperative infections. However, this association was disturbed when correcting for weight, surgical complexity and lowest intraoperative temperature in multivariable analysis.

Conclusions: In pediatric cardiac surgery, longer duration of CPB in itself is not associated with postoperative infections. Therefore, other factors are likely to contribute to the high incidence of postoperative infections after pediatric cardiac surgery.

\section{CURRENT STRATEGIES TO REDUCE COAGULASE NEGATIVE STAPHYLOCOCCUS (CONS) IN THE NEONATAL UNIT \\ V. Venugopalan}

Neonatal Unit, John Radcliffe Hospital, Oxford, UK

Aim: To evaluate whether strict aseptic procedures reduces the CONS positive blood cultures.

Methods: In our neonatal unit, any procedure involving skin breakdown is done in a sterile aseptic procedure (from $1^{\text {st }}$ September 2008). We analysed all positive blood cultures from the neonatal unit from November 2007 to October 2009 (10 months before the intervention and 13 months after). We analysed the positive blood cultures in relation to the number of admissions in the unit and the Intensive care/High dependency activity in the neonatal unit in the same month. Statistical analysis was using two sample independent " $t$ " test.

Results: The number of CONS positive cultures reduced by $75 \%$ in the first 3 months and $40-50 \%$ in the subsequent 10 months. ( $p 0.008,95 \% \mathrm{Cl}(0.75$ $-4.45)$. There was reduction in the CONS positive cultures in relation to the number of admissions ( $p$ $0.025,95 \% \mathrm{Cl}(0.45-7.1)$. In relation to the Intensive care/High dependency activity, there was a $70-80 \%$ reduction in the CONS positive cultures in the first 3 months and $40-50 \%$ reduction in the latter 10 months. ( $p 0.01,95 \% \mathrm{Cl}(0.21-1.48)$.

Conclusion: CONS is a common nosocomial infection in the neonatal unit. Our incidence is about 7-10/1000 live births (some could be contamination without infection). There was reduction in the number of positive CONS post introduction of above precautions and the reduction was also seen in relation to the number of admissions and to ITU/ HDU activity. However, they need to be monitored regularly and kept under strict surveillance.

\section{9}

FATAL ENTEROVIRAL MYOCARDITIS IN $30+2$ WEEKS GESTATION MONOCHORIONIC DIAMNIOTIC TWINS

\author{
V.M. Shivamurthy, A.K. Sapare, V. Kairamkonda \\ Neonatal Unit, University Hospitals of Leicester, \\ Leicester, UK
}

Monochorionic Diamniotic twins were born at 30+2 weeks gestation by Emergency caesarean section 
for foetal distress in one of the twins. Mother was Gravida 3 Para 2 with no known medical illness and normal antenatal scans but was colonised with Group B Streptococcus. The twins were born in good condition but needed ventilation soon after birth.

Twin 1 was extubated after 24 hours of ventilation. She deteriorated and had to be re-ventilated and was treated for possible meningitis. Her initial ECHO showed large PDA with left ventricular overload and the PDA was medically treated. She deteriorated further and $\mathrm{ECHO}$ at this stage showed severe left ventricular dysfunction with Pulmonary Hypertension requiring inotropes to maintain BP. ECG showed significant ST changes and troponin was significantly raised suggesting myocardial injury. Repeat $\mathrm{ECHO}$ showed dilated hypokinetic left ventricle, tense left atrium and bulging right atrium.

Twin 2 was also extubated after brief ventilation. She had to be re-ventilated because of significant pulmonary haemorrhage. She was haemodynamically unstable needing Inotropes and initial ECHO showed large PDA with high pulmonary pressures. She then developed recurrent narrow complex tachycardia. Repeat ECHO showed poor left ventricular function, left atrium and left ventricle moderately dilated, good right ventricle function. ECG showed gross ST changes.

Both the twins died of poor cardiac function with no output. Post mortem in both of them showed macroscopic and microscopic changes only in Left side of the heart with right side remaining unaffected.

Enterovirus DNA was detected in serum by PCR.

\section{0}

\section{PREDICTED AND MEASURED PAGIBAXIMAB SERUM LEVELS IN HIGH-RISK NEONATES}

\author{
J.F. Kokai-Kun', D. Mould², L.E. Weisman³, \\ B. Bloom ${ }^{4}$, F. Eyal ${ }^{5}$, M. Polack ${ }^{6}$, J. Fretz ${ }^{1}$, C. Sei ${ }^{1}$, \\ J.J. Mond ${ }^{1}$
}

${ }^{1}$ Biosynexus Incorporated, Gaithersburg, MD, ${ }^{2}$ Projections Research Inc, Phoenixville, PA, ${ }^{3}$ Baylor College of Medicine, Houston, TX, ${ }^{4}$ Wesley Medical Center, Witchita, KS, '5SA Women's and

Children's Hospital, Mobile, AL, 'West Virginia

University Hospital, Morgantown, WV, USA

Pagibaximab, a monoclonal antibody for prevention of staphylococcal sepsis in VLBW infants reported no staphylococcal sepsis when serum levels were $\geq 500 \mathrm{ug} / \mathrm{ml}$. Prior to phase 3 studies, we sought to develop a dosing scheme to maintain pagibaximab serum levels $\geq 500 \mathrm{ug} / \mathrm{ml}$ for 35 days in VLBW infants. Serum levels from 100 VLBW infants infused with pagibaximab 10 to $90 \mathrm{mg} / \mathrm{kg}$, for one to three doses were used to develop a pharmacokinetic model and dosing regimen. This regimen was prospectively evaluated in planned and scavenged samples obtained for 35 days from VLBW infants infused with pagibaximab. Observed and predicted pagibaximab levels were compared. The pharmacokinetics described the concentration time course of pagibaximab as a two compartment model with linear central compartment elimination. Pharmacokinetic parameters from this model were (mean \pm SE): Cl (ml/h) 0.446, VI 75, V2 138, COint 12.3, Ke $0.000836, \mathrm{t} 1 / 215.4$ days. Using this model a dosing scheme of $100 \mathrm{mg} / \mathrm{kg}$ daily for 3 days and then weekly for 3 weeks was developed to maintain target levels. Observed pharmacokinetic estimates from infants who received this regimen from both scavenged and planned samples were similar and as predicted by the model. Inclusion of scavenged samples caused some model instability due to lack of accurate sampling times. In either set of samples, all serum levels were $\geq 500 \mathrm{ug} / \mathrm{ml}$. We developed a dosing regimen for pagibaximab in VLBW infants to maintain serum levels of $\geq 500 \mathrm{ug} /$ $\mathrm{ml}$ and prospectively confirmed this regimen. Phase 3 studies can proceed with confidence that pagibaximab target levels can be achieved and maintained.

\section{1}

\section{PROCALCITONIN, INTERLEUKIN-6, LIPOPOLYSACCHARIDE-BINDING PROTEIN AND C-REACTIVE PROTEIN IN THE DIAGNOSIS OF SEPSIS OF FEBRILE NEUTROPENIC CHILDREN}

\section{Kitanovski ${ }^{1}$, T. Gmeiner-Stopar ${ }^{2}$, M. Derganc ${ }^{3}$}

${ }^{1}$ Dept. of Hemato-oncology, University Medical Centre, ${ }^{2}$ Nuclear Medicine Dept., ${ }^{3}$ Dept. of Pediatric Surgery and Intensive Care, University Medical Center Ljubljana, Ljubljana, Slovenia

Background and aims: The diagnosis of sepsis in children with febrile neutropenia (FN) remains difficult. The aim of the study was to evaluate the role of procalcitonin (PCT), interleukin-6 (IL6 ), lipopolysaccharide- binding protein (LBP) and C-reactive protein (CRP) in the diagnosis of bacteremia and sepsis of children with $\mathrm{FN}$. 